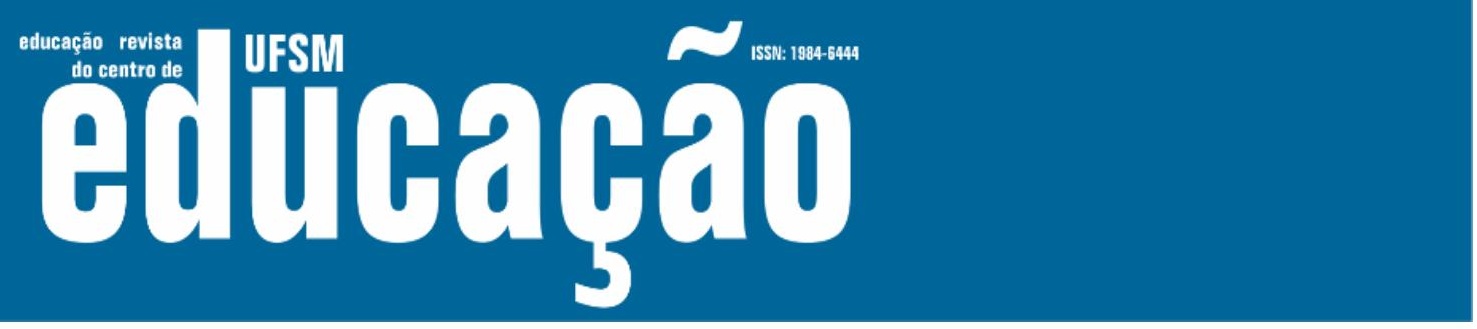

ISSN: 1984-6444 | http://dx.doi.org/10.5902/1984644436242

\title{
Ensino de História: Educação Histórica no contexto de mudanças das práticas pedagógicas (Paraná, 2008).
}

\author{
History Teaching: Historical Education in the context of changes in \\ pedagogical practices (Paraná, 2008).
}

\begin{abstract}
Sueli de Fátima Dias
Doutoranda na Universidade Estadual de Londrina. Londrina, Paraná, Brasil.

Professora na Faculdade de Apucarana e na rede pública da Secretaria de Estado da Educação. sueli.dias@bol.com.br - https://orcid.org/0000-0001-6691-5228

\section{Marlene Rosa Cainelli}

Professora doutora na Universidade Estadual de Londrina. Londrina, Paraná, Brasil. Investigadora do Centro de Investigação Transdiciplinar Cultura, Espaço e Memória, da Universidade do Porto, em Portugal.

cainelli@uel.br - https://orcid.org/0000-0002-9709-3834
\end{abstract}

Recebido em 31 de dezembro de 2018

Aprovado em 30 de abril de 2019

Publicado em 24 de junho de 2020

\section{RESUMO}

Neste artigo partimos do contexto de discussão do ensino de História e suas relações no currículo escolar brasileiro considerando o surgimento de diferentes práticas pedagógicas. Apresentamos estudos acerca da conjuntura das mudanças de fins do século XX e incorporação de novos paradigmas ao ensino da disciplina como a Educação Histórica. Ressaltamos, conforme as Diretrizes Curriculares de História, no Estado do Paraná (DCE-SEED-PR/2008), um aporte teórico-metodológico embasado na compreensão da consciência histórica e elementos que se relacionam com a Educação Histórica, indicando à atuação pedagógica do professor a associação entre passado-presente, produção de narrativas e a aula oficina. Este artigo integra-se às investigações da tese de doutoramento em desenvolvimento na Universidade Estadual de Londrina intitulada - Educação Histórica na formação e atuação dos professores: um campo em construção para os docentes da rede pública - SEED-PR, ressaltando a expansão das discussões em torno da temática da Educação Histórica que, em nossas hipóteses, influencia a formação e atuação de professores de História ressignificando suas práticas.

Palavras-chave: Ensino de História; Formação de professores; Educação Histórica; Diretrizes Curriculares de História /SEED-PR. 


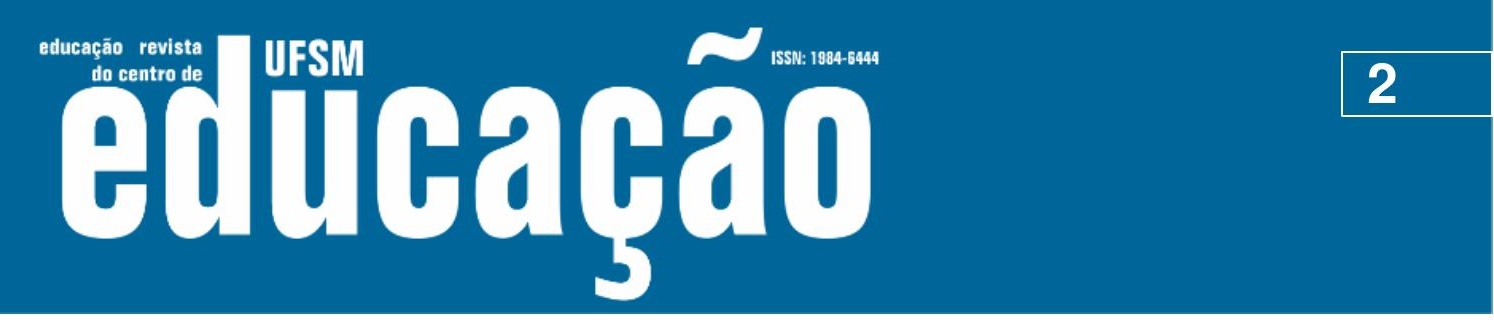

ISSN: 1984-6444 | http://dx.doi.org/10.5902/1984644436242

\section{ABSTRACT}

This article starts from the context of discussion about history teaching in which arise different pedagogical practices and its relations with Brazilian school curriculum. The article exposes the introduction of History Education in the context of changes in the end of the XX century and the incorporation of new paradigms in the teaching of this school subject. It presents, according to the History Curricular Guidelines in the state of Paraná (DCE-SEED-PR/2008), a new theoretical and methodological input, grounded in the comprehension of historical consciousness and elements related to History Education, suggesting to the teacher's exercise the association between pastpresent, narratives production and classroom-workshop. It is integrated to the studies from the doctoral thesis developed at State University of Londrina, named History Education in the formation and performance of teachers: a field under construction for teachers of the Appropriations as a methodology to teach History: a developing field in the pedagogical practices of teachers from the public network SEED-PR, highlighting the expansion of this new rationality as a field of research in historical cognition, influencing the formation and performance of teachers and giving new meaning for the history teaching.

Keywords: History Teaching; Teacher training; History Education; History Curricular Guidelines/SEED-PR.

\section{Introdução}

As discussões a respeito do ensino de História, desde fins do século XX e neste início de século XXI, consolidaram a temática como objeto de pesquisa e apresentaram reorientações para práticas pedagógicas. Abordaram questões envolvendo linguagens e metodologias de ensino apontando que as reflexões, com muito ainda a se expandirem, tangenciam compreensões mais aprofundadas das teorias da História e seu espaço como ciência.

Nessa investigação, a partir da interlocução com professores da Escola Básica, no Estado do Paraná, foi se firmando a necessidade de conhecer como os professores em serviço, sujeitos dos programas e ações da formação continuada, acompanham as discussões acerca do ensino de História e que interações fazem com tais discussões.

Partimos da retomada de elementos que compõem esse movimento nas últimas três ou quatro décadas e abordamos o surgimento da Educação Histórica. 


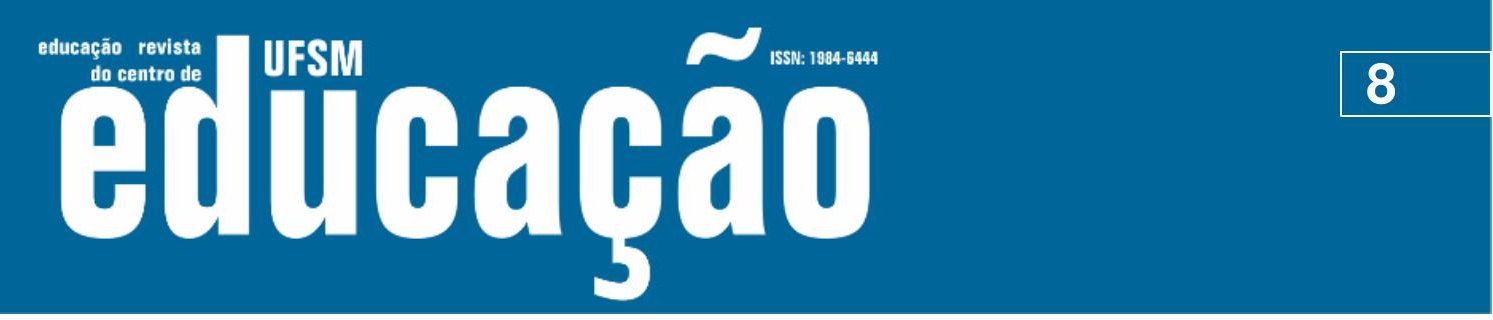

ISSN: 1984-6444 | http://dx.doi.org/10.5902/1984644436242

História do Brasil. De maneira geral, mantinha-se o estudo de atos políticos, a exaltação de personagens como modelos de civismo e nacionalidade (BITTENCOURT, 2004).

As mudanças que foram surgindo, ainda que não pretendessem se tornar modelos, foram apresentando experiências alternativas na utilização de "diferentes linguagens e recursos de ensino, tais como música, literatura, filmes, TV, história em quadrinhos e outros documentos" (FONSECA, 2006, p.86). No entanto, a maior contribuição foi que, no intuito de ressignificar o ensino de História, iniciou-se um processo que se consolidou e se estende aos dias de hoje, como nos reforçam as pesquisas na área, pois

Há cerca de quatro décadas vimos assistindo à introdução de novas
concepções da história, que já alcançaram a organização de currículos e a
atuação de professores e que modificam o ensino e promovem inovações
teóricas e métodos renovados, substituindo as velhas práticas consagradas
de ensinar história, que valorizavam sobretudo, o fato político, o herói e a
data. Concepções renovadas da disciplina e conduziram em busca de novos
objetos, de novos temas e sujeitos que passaram a compor os currículos
escolares e mostraram caminhos trilhados pela pesquisa sobre o ensino de
história, ao buscar o significado para sua existência. (ABUD, 2013, p.10)

As mudanças e propostas de reorganização do ensino de História, assim como para outras disciplinas, pautaram-se nas deliberações da nova LDB, Lei nº 9.304/96, nos Parâmetros Curriculares Nacionais (PCNs) de 1997-1998, na formulação de Diretrizes Curriculares para a formação de professores e orientações disciplinares, entretanto, para a recolocação da disciplina em seu lugar mais apropriado, ainda carecia de fundamentação de um novo paradigma, pois

os processos de aprendizado da História precisam ser pensados para além de serem considerados como processos dirigíveis e controláveis, mas, em que pese o fato de estar ainda em construção uma teoria da aprendizagem histórica referenciada em uma cognição situada na própria História, isso pode ser fecundado por concepções teóricas do aprendizado histórico que tenham como finalidade principal a formação e desenvolvimento da consciência histórica, constituindo-se, assim, a possibilidade de uma relação mais orgânica entre a cultura histórica e a cultura escolar de uma sociedade. (SCHMITD, 2012, p.88)

Diante das perspectivas configura-se a compreensão de que aprender História é, sobretudo, transformar informações em conhecimento e a finalidade do ensino da disciplina nos currículos escolares, além de oferecer referenciais para as orientações 


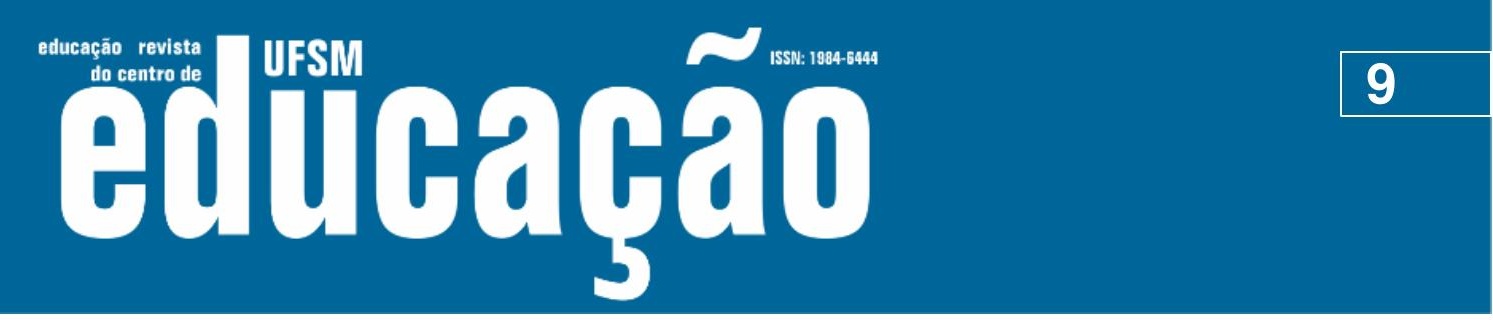

ISSN: 1984-6444 | http://dx.doi.org/10.5902/1984644436242

temporais e atitudes da vida prática deve ser

levar à população os conteúdos, temas, métodos, procedimentos e técnicas que o historiador utiliza para produzir conhecimento histórico, ressalvando que não se trata de transformar todas as pessoas em historiadores, mas de ensinar a pensar historicamente (SCHMITD; URBAN, 2018, p. 14).

Pensar historicamente é um dos primeiros passos para demonstrar que sujeitos têm compreensões próprias do passado e são capazes de, a partir do aprendizado da História que construíram, promover mudanças sociais no meio em que vivem.

\section{Educação Histórica no ensino de História}

No bojo de tais mudanças, tem surgido no Brasil, a partir do ano de 2000, em interação com as reformulações para o ensino de História na Inglaterra, Alemanha e Portugal, desde fins do século XX, um novo pressuposto teórico-metodológico nominado por Educação Histórica. De acordo com Ramos (2013, p. 4), "pesquisadores deste campo, investigam como alunos e/ou professores pensam, como agem, como vivenciam seu cotidiano escolar, destacando 0 ensino/aprendizagem de História." Para Schmitd e Urban (2018), é uma concepção promotora de uma revolução copernicana no ensino de História, porque inverte o processo de compreensão do ensino embasado, unicamente, nos pressupostos da pedagogia e da psicologia cognitiva, ainda que não os abandone, reforçando os referenciais da ciência e teoria da História.

Nesse contexto de expansão das ideias da Educação Histórica, vem se formando uma rede de pesquisas a partir de núcleos acadêmicos e pesquisadores organizados em laboratórios de ensino, programas de pós-graduação e projetos de formação de professores em caráter inicial ou continuado, em universidades como a Universidade Federal do Paraná (UFPR), Universidade Estadual de Londrina (UEL), Faculdade de Educação da Universidade de São Paulo (FEUSP), Universidade Federal do Mato Grosso (UFMT), Universidade Federal da Integração LatinoAmericana (UNILA), Universidade Federal de Goiás (UFGO), entre outras que abordam o ensino de História a partir dessa nova racionalidade. 


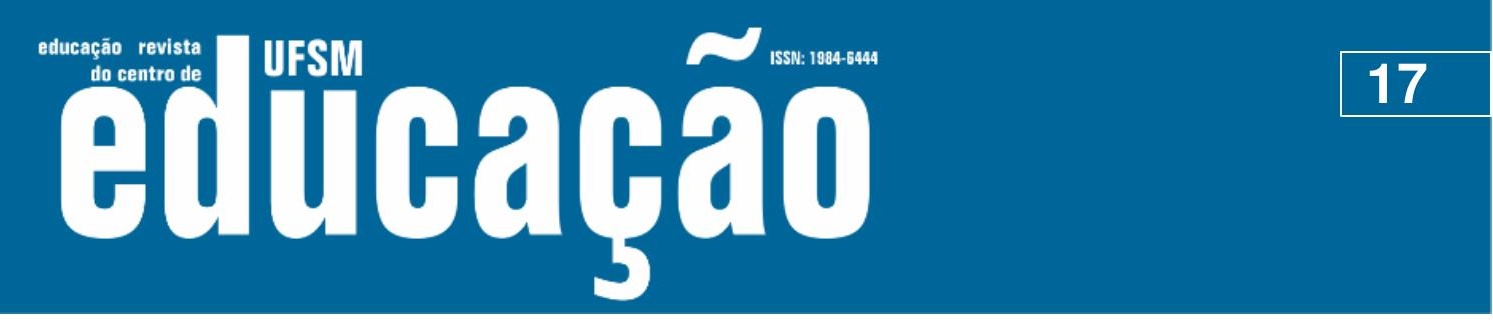

ISSN: 1984-6444 | http://dx.doi.org/10.5902/1984644436242

conhecimento histórico como compreensão das relações humanas, da realidade em que vivemos e das ações que orientam o presente com as perspectivas de construção do futuro.

\section{Considerações finais}

O processo de discussões a respeito do ensino de História tem avançado significativamente, fundamentando as ações de como e por que ensinar e aprender História.

Nesse contexto, especialmente a partir das duas últimas décadas, a Educação Histórica tem se apresentado como aporte teórico-metodológico, reforçando as relações do ensino com a teoria da História e sua importância como ciência. Tem sido abordada em pesquisas que investigam a cognição em História, em documentos que norteiam a prática pedagógica de professores como as DCEs de História, no Estado do Paraná e em programas de formação continuada.

Dentre as inúmeras análises podemos considerá-la uma proposta epistemológica relacionada à construção do conhecimento científico, contribuindo com reflexões da importância e funções do ensino de História e, fundamentalmente, na atribuição de sentido e orientações para a vida prática dos sujeitos.

\section{Referências}

ALVES, Ronaldo Cardoso. História e vida: o encontro epistemológico entre didática da história e educação histórica. In. História \& Ensino. Londrina, vol. 19, №.1, p.4969, jan/jun. 2013.

ABUD, Katia. Combates pelo ensino de história. In: ARIAS NETO, José Miguel. (Org). Dez anos de pesquisas em ensino de História: VI encontro nacional de pesquisadores de ensino de História. Londrina: AtritoArt, 2005. p. 50-55.

ABUD, Katia. Manter e renovar o ensino de história. In: SILVA, Marcos (org) História - que ensino é esse? Campinas: Papirus, 2013. p. 9-12.

BARCA, I. Ideias chave para a educação histórica: uma busca de (inter) identidades. História Revista, v. 17, n. 1, p. 2, 2012

BITTENCOURT, Circe. Maria. Ensino de História: fundamentos e métodos. São Paulo: Cortez, 2004. 


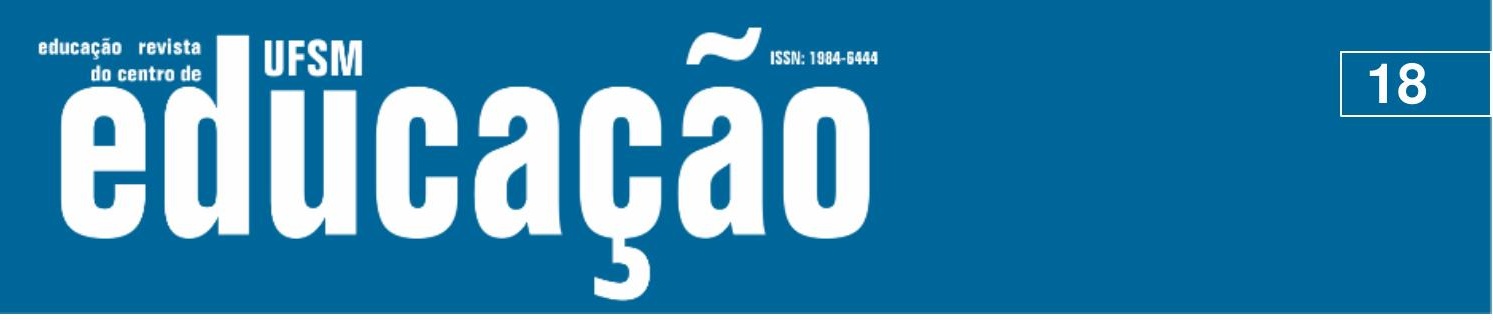

ISSN: 1984-6444 | http://dx.doi.org/10.5902/1984644436242

CAINELLI, Marlene Rosa; OLIVEIRA, Sandra Regina Ferreira de. A relação entre o aprendizado histórico e formação histórica no processo de ensinar história para crianças. In: CAINELLI, Marlene Rosa.; SCHMITD, Maria Auxiliadora Moreira Santos. Educação Histórica: teoria e pesquisa. ljuí, 2011.

CARRETERO, Mario. Construtivismo e educação. Porto Alegre: Artemed, 1997.

CHARMAZ, K. A construção da teoria fundamentada: guia prático para análise qualitativa. Porto Alegre (RS): Artmed; 2009.

FONSECA, Selva Guimarães. Didática e prática de ensino de História: experiências, reflexos e aprendizados. Campinas: Papirus, 2006.

FONSECA, Selva Guimarães. A história na Educação Básica: conteúdos, abordagens e metodologias. In: Anais do I Seminário Nacional: Currículo em Movimento perspectivas atuais. Belo Horizonte, novembro de 2010. Disponível em http://portal.mec.gov.br/index.php?option=com_content\&view=article\&id=16110\&ltem id=936. Acesso em 15 nov. 2017.

NADAI, Elza. O ensino de história no Brasil: trajetória e perspectiva. Rev. Bras. de História. São Paulo, vol. 13, n. 25/26, p.143-162, set.92/ago.93.

OLIVEIRA, Nucia Alexandra Silva de. Isabel Barca: caminhos trilhados pela Educação Histórica. Rev. Antíteses, v. 5, n. 10, p. 865-874, jul./dez. 2012.

PARANÁ. Secretaria de Estado da Educação do Paraná. Diretrizes Curriculares da Educação Básica. História. $2008 . \quad$ Disponível em http://www.educadores.diaadia.pr.gov.br/arquivos/File/diretrizes/dce_hist.pdf. Acesso em 01 dez. 2017.

RAMOS, Marcia Elisa Teté. Educação Histórica: articulação entre investigação e ação. In. XIV Jornadas Interescuelas/Departamentos de Historia. Departamento de Historia de la Facultad de Filosofía y Letras. Universidad Nacional de Cuyo, Mendoza, 2013. Disponível em http://cdsa.aacademica.org/000-010/1110. Acesso em 23 nov. 2017.

RÜSEN, Jorn. Razão histórica: teoria da história: os fundamentos da ciência histórica. Brasília: Editora UNB, 2001.

RÜSEN, Jorn. O desenvolvimento da competência narrativa na aprendizagem histórica: uma hipótese ontogenética relativa à consciência moral. In. SCHMIDT, Maria Auxiliadora Moreira; BARCA, Isabel; MARTINS, Estevão de Rezende. (orgs) Jörn Rüsen e o ensino de História. Curitiba: Editora UFPR, 2010.

RÜSEN, Jorn. Teoria da História: Uma teoria da história como ciência. Tradução de Estevão C. de Rezende Martins. Curitiba: UFPR, 2015. 


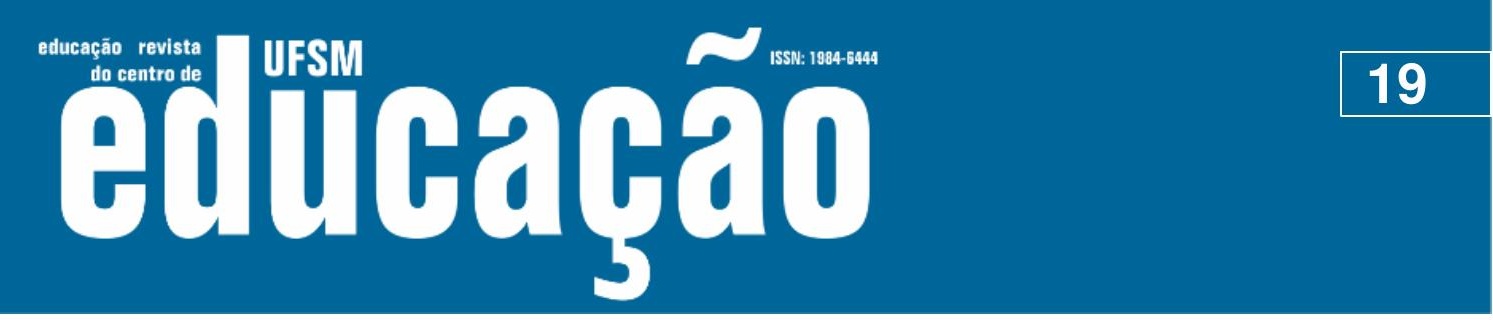

ISSN: 1984-6444 | http://dx.doi.org/10.5902/1984644436242

SACRISTÁN, José Gimeno. Introdução - A função aberta da obra e seu conteúdo. In: SACRISTÁN, José Gimeno. Saberes e incertezas sobre o currículo. Porto Alegre: Penso, 2013. p. 9-14.

SACRISTÁN, José Gimeno. O que significa o currículo. In: SACRISTÁN, José Gimeno. Saberes e incertezas sobre o currículo. Porto Alegre: Penso, 2013. p. 1635.

SADDI, Rafael. Didática da História na Alemanha e no Brasil: considerações sobre o ambiente de surgimento da neu geschichtsdidaktik na Alemanha e os desafios da nova didática da história no Brasil. Rev. Opsis, Catalão, v. 14, n. 2, p. 133-147, 2014.

SCHMIDT, Maria Auxiliadora Moreira; CAINELLI, Marlene Rosa. Ensinar História. São Paulo: Scipione, 2004.

SCHMIDT, Maria Auxiliadora Moreira. História do ensino de História no Brasil: uma proposta de periodização. História da Educação, v. 16, n. 37, p. 73-91, 2012.

SCHMIDT, Maria Auxiliadora Moreira; BARCA, Isabel. Uma epistemologia da pesquisa em Educação Histórica - Limites e possibilidades. In. SCHMIDT, Maria Auxiliadora Moreira; BARCA, Isabel; URBAN; Ana Cláudia. Passados Possíveis- A educação Histórica em Debate. Editora Unijui, 2014, p.21 a 40.

SCHMITD. Maria Auxiliadora Moreira; GARCIA, Tania Braga. A formação da consciência histórica de alunos e professores e o cotidiano em aulas de História. Caderno Cedes. Campinas, v.25, n.67, p. 207-308, set./dez. 2005. Disponível em A formação da consciência histórica de alunos e professores e o cotidiano em aulas de História Acesso em 24 jul. 2017.

SCHMITD. Maria Auxiliadora Moreira; URBAN, Ana Claudia. Por que Educação Histórica? In: SCHMITD. Maria Auxiliadora Moreira; URBAN, Ana Claudia. (orgs.) 0 que é Educação Histórica. Curitiba: W. A. Editores, 2018. Col. Educação Histórica.

SILVA, Marcos. A história vem a público. In: SILVA, Marcos (org) História - que ensino é esse?. Campinas: Papirus, 2013. p. 15-30.

ZAMBONI, Ernesta. Digressões sobre a educação e o ensino de história no século XXI. História e Ensino: Londrina, v.11, p. 07-22, jul. 2005.

\section{Correspondência}

Sueli de Fátima Dias - Universidade Estadual de Londrina - Rodovia Celso Garcia Cid - Pr 445 Km 380, CEP 86057-970, Campus Universitário, Londrina, Paraná, Brasil.

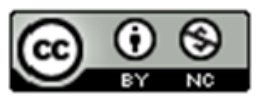

This work is licensed under a Creative Commons Attribution-NonCommercial 4.0 International (CC BY-NC 4.0) 